\title{
Is the Decade of Action on Nutrition (2016-2025) leaving a footprint? Taking stock and looking ahead
}

\author{
Lina Mahy ${ }^{1}$ and Trudy Wijnhoven ${ }^{2}$
}

Suggested citation Mahy L and Wijnhoven T. Is the Decade of Action on Nutrition (2016-2025) leaving a footprint? Taking stock and looking ahead. Rev Panam Salud Publica. 2020;44:e73. https://doi.org/10.26633/RPSP.2020.73

Thanks to the strong leadership of Brazil, among others, the United Nations (UN) Decade of Action on Nutrition ("Nutrition Decade") was proclaimed in 2016 by the UN General Assembly. (1) The Nutrition Decade reaches its mid-term in 2020. The time has come to review the progress made so far in the six action areas of the Nutrition Decade's Work Programme and identify areas in need of accelerated action and priority investment during the remaining period until 2025.

Advocacy efforts during the first half of the Nutrition Decade on the importance of nutrition, healthy diets, and food systems for human and planetary health are showing results. The evidence of unhealthy diet and malnutrition being a key risk factor for disease and death globally is unequivocal.(2) Global attention to the critical role of sustainable, resilient food systems for healthy diets and improved nutrition has never been as prominently present as we are observing today. Brazil is one of the first countries to recognize agroecology and biodiversity, and incorporate sustainability issues in their innovative, holistic national food-based dietary guidelines.(3) A clear understanding of the effective interventions to be delivered by health systems has emerged. Voluntary or mandatory reformulation of processed food products is increasingly implemented by food industry stakeholders. More and more scientists break silos and work collectively across different sectors towards offering models to better predict impact of actions or inaction on nutrition, design more effective and innovative solutions to address malnutrition in all its forms and define appropriate metrics to monitor progress and ensure accountability.(4) Nations, regions, cities, and communities are collaborating in new ways in what is called this "new nutrition reality"(5) and, importantly, people demand transparency on and exert urgency over decisions impacting their diet, their health, their environment.

There has been significant progress in generating commitments and new financing for nutrition. Brazil was the first country that formally submitted country-specific commitments under the Nutrition Decade that focused on reversing the increasing trend in adult obesity, reducing the consumption of sugar-sweetened beverages and increasing the consumption of fruits and vegetables. The Brazilian Intersectoral Strategy to Prevent and Control Obesity has been a strategic framework to work on these commitments. Ecuador submitted formally commitments, inter alia, related to fiscal policies on sugar-sweetened beverages, breastfeeding and prenatal care with the aim to tackle all forms of malnutrition throughout the life cycle and to generate actions that address the determinants of health and nutrition. Italy was the third country that committed to set up a national working group with a multisectoral and multistakeholder composition to advance the national nutrition agenda.(6)

The Nutrition Decade encourages and supports countries to strengthen collaboration and align nutrition action by establishing action networks. These informal coalitions of countries focus on a specific nutrition-related area with the aim to exchange knowledge and good practices, illustrate successes and challenges, and provide mutual support to accelerate progress in specific areas, with the final objective of improving food systems, diets and nutrition for all through the adoption of coherent policies and legislation. At the global level, action networks have been established on themes such as sustainable foods from the oceans and inland waters for food security and nutrition (Norway); nutrition labelling (France, Australia and Chile); traditional, healthy and sustainable diets (Italy); and on the provision of healthy school meals (Germany). Additionally, several regional networks have been convened in the Region of the Americas, such as the ones that are led by Brazil jointly with other countries on the public purchasing of familyproduced food (7), sustainable school food procurement, strategies for reducing salt consumption for the prevention and control of cardiovascular diseases, and food and nutrition security governance.

Despite these positive developments, however, hunger is still on the rise, and malnutrition in all its forms is affecting people worldwide with growing patterns of inequality.(8) 
An acceleration of efforts is needed in order to have, inter alia, food systems delivering healthy diets in a sustainable way, nutrition-related actions integrated into national health systems and universal health coverage plans, responsible investments in agriculture and food increased and coherence between trade policy and nutrition action ensured. The mid-term review of the Nutrition Decade is an excellent opportunity to reflect, re-align and re-commit, more determined and more powerful than ever to advance the global nutrition agenda, and to ensure that, by
2025, access to healthy, safe, and affordable diets for all, at all times, becomes a reality.

Disclaimer. The authors alone are responsible for the views expressed in this article and they do not necessarily represent the views, decisions or policies of the institutions with which they are affiliated, nor the opinion or policy of the RPSP/PAJPH and/or the Pan American Health Organization.

\section{REFERENCES}

1. UN Decade of Action on Nutrition 2016-2025 [website]. Available at www.un.org/nutrition/ Accessed on May 222020

2. GBD 2017 Diet Collaborators. Health effects of dietary risks in 195 countries, 1990-2017: a systematic analysis for the Global Burden of Disease Study 2017. Lancet. 2019;393(10184): 1958-72. Available at www.thelancet.com/article/S0140-6736(19)30041-8/fulltext Accessed on May 222020.

3. Bortolini GA, Moura ALP, Lima AMC, Moreira HOM, Medeiros $\mathrm{O}$, Diefenthaler ICM, et al. Guias alimentares: estratégia para redução do consumo de alimentos ultraprocessados e prevenção da obesidade. Rev Panam Salud Publica. 2019;43:e59. https://doi. org/10.26633/RPSP.2019.59

4. UN Decade of Action on Nutrition Secretariat. Mid-term review foresight paper; 2020. Available at www.un.org/nutrition/sites/ www.un.org.nutrition/files/general/pdf/nutrition_decade_mtr_ background_paper_en.pdf Accessed on May 222020.
5. Branca F, Demaio A, Udomkesmalee E, Baker P, Aguayo VM, Barquera $S$ et al. A new nutrition manifesto for a new nutrition reality. Lancet. 2020;395(10217):8-10 doi: https://doi.org/10.1016/ S0140-6736(19)32690-X

6. UN Decade of Action on Nutrition Commitments Database [website]. Available at www.un.org/nutrition/commitments/database Accessed on May 222020.

7. Bocchi CP, Magalhães ES, Rahal L, Gentil P, Gonçalves RS. A década da nutrição, a política de segurança alimentar e nutricional e as compras públicas da agricultura familiar no Brasil. Rev Panam Salud Publica. 2019;43:e84. https:/ /doi.org/10.26633/RPSP. 2019.84

8. FAO, IFAD, UNICEF, WFP and WHO. The State of Food Security and Nutrition in the World 2019. Safeguarding against economic slowdowns and downturns. Rome: FAO; 2019. Available at www. fao.org/3/ca5162en/ca5162en.pdf. Accessed on May 222020. 